\title{
Studies on the "Low Dose" Suppressible Cushing's Disease
}

\author{
NAOKATA SHIMIZU AND HISAYOSHI YOSHIDA
}

\author{
The First Department of Internal Medicine, Teikyo University, \\ School of Medicine, Itabashi-ku, Tokyo 173, Japan
}

\begin{abstract}
Synopsis
Diagnosis of Cushing's disease in most cases can be established by the standard dexamethasone suppression test without difficulty. However, some cases were known to be normally suppressed by the standard low dose of dexamethasone ( $2 \mathrm{mg}$ daily). The case we encountered recently was also normally suppressed by either the rapid (Nugent) or the standard (Liddle) method. This fact prompted us to study the usefulness of a single dose of $0.5 \mathrm{mg}$ of dexamethasone to suppress the plasma cortisol in the normal.

It was concluded that the single oral dose of $0.5 \mathrm{mg}$ of dexamethasone given at 11 p.m. on the previous night suppressed the plasma cortisol efficiently the following morning in the normal, thus making the differentiation of particular cases of Cushing's disease from the normal possible. The disappearance of plasma dexamethasone did not differ significantly between the normal and the Cushing's disease.
\end{abstract}

The diagnosis of the Cushing's disease is established on the basis of the unsuppressibility of the urinary 17-hydroxycorticosteroids after the oral dose of dexamethasone $(2 \mathrm{mg}$ and $8 \mathrm{mg}$ ), daily according to the Liddle's regimen (Liddle, 1969). Also, the rapid suppression test according to the Nugent method (Nugent et al. 1965) is widely used to sort out the Cushing's syndrome from the normal. By these methods, together with the metyrapone test, $\mathrm{ACTH}$ test and frequent sampling of the plasma cortisol, the diagnosis of Cushing's disease in most cases is made without many difficulties. However, according to the cooperative studies sponsored by the Japanese Welfare Ministry, 11 cases of Cushing's disease out of 178 were normally suppressed by the daily administration of $2 \mathrm{mg}$ of dexamethasone.

Received for publication July 17, 1976.
The case we encountered recently was also normally suppressed by both Nugent's and Liddle's method. The present paper is to describe the usefulness of the lower dose of dexamethasone to sort out such a "low dose" suppressible Cushing's disease from the normal. The "low dose" in this paper is designated as $2 \mathrm{mg}$ dose of dexamethasone per day as in Liddle's and $1 \mathrm{mg}$ single dose as in Nugent's method.

\section{Case Report}

S. M. was referred to the Teikyo University Hospital at the age of 36 in 1974 with a tentative diagnosis of Cushing's disease. Her illness appeared to start at the age of 25, gaining body weight $(53 \mathrm{~kg}$ to $83 \mathrm{~kg})$. In the following years, she noticed purple striae in forearms and abdomen, plethoric face, headache and 
thick lanugo. At the age of 36, she experienced an episode of fever, nausea and vomitting which forced her to enter an hospital where a tentative diagnosis of Cushing's disease was made.

Studies on signs and symptoms on admission revealed the presence of moon face, plethoric face, hirsutism, white striae cutis on her abdomen, central obesity, mild hypertension, impaired glucose tolerance test and dysmenorrhoea, but without muscle weakness, easy brusiability or hypokalemia. As shown in Fig. 1, her basal urinary 17-OHCS ranged from $9.5 \mathrm{mg} /$ day to $13.2 \mathrm{mg} /$ day and was suppressed to $1.5 \mathrm{mg} /$ day and $0.1 \mathrm{mg} /$ day after the oral administration of $2 \mathrm{mg}$ of dexamethasone per day. The plasma cortisol in the morning was $12.5 \mu \mathrm{g} / \mathrm{d} l$, and in the evening was $18.0 \mu \mathrm{g} / \mathrm{d} l$. Continuous determination of her urinary 17-OHCS revealed no marked periodic variation of her basal output of cortisol.

Among the studies performed, the rapid suppression test using a single oral dose of $0.5 \mathrm{mg}$ dexamethasone revealed the abnormal suppressibility as shown in the following results. She received a pituitary irradiation without improvements of clincal and laboratory findings. The rapid suppression test either by $1.0 \mathrm{mg}$ or by $0.5 \mathrm{mg}$ dexamethasone revealed exactly the same pattern of suppressibility after the irradiation. In March, 9 months after the termination of irradiation, she was operated for the bilateral adrenalectomy. The adrenals were hyperplastic and the right adrenal weighed $6.3 \mathrm{~g}$ and the left $8.0 \mathrm{~g}$. She is placed on $20 \mathrm{mg}$ cortisol and lives uneventfully. Insufficient time has elapsed to observe any marked clinical improvement on her.

\section{Materials and Methods}

Plasma cortisol was measured by radioimmunoassay. The urinary 17-OHCS was measured by Porter-Silver's method after $\beta$-glucuronidase hydrolysis. Plasma dexamethasone was measured by the modification of Lee's method (Lee and Osawa, 1974), after a Saffaroni type paper chromatography (stationary phase: formamide, mobile phase benzene: chloroform) to separate dexamethasone and cortisol (Meikle et al., 1973).
URINARY 17 OHCS

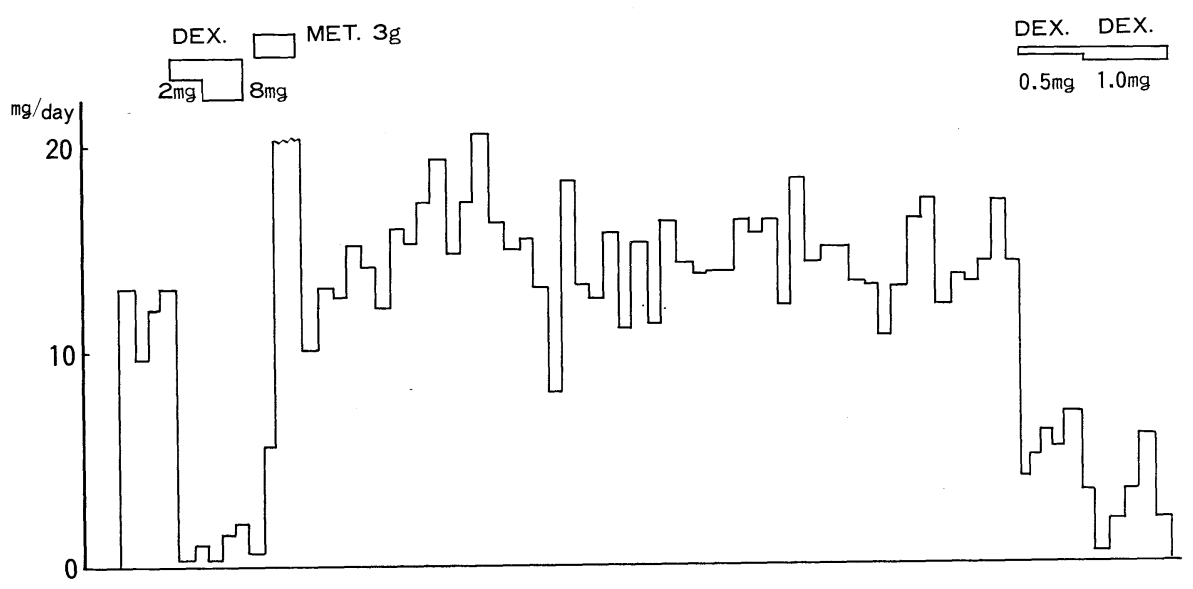

Fig. 1. Urinaly 17-OHCS in a "low dose" suppressible Cushing's disease, M. S. 


\section{Results}

Normal :

Twenty-seven out-patients were given a single oral dose of $0.5 \mathrm{mg}$ dexamethasone at 11 p.m. and the plasma cortisol was determined in the following morning between 6 and 9 a.m. Some of them were given a different dose on other occasions. As shown in Table 1, the highest plasma cortisol in the following morning after $0.5 \mathrm{mg}$ dexamethasone was $4.1 \mu \mathrm{g} / \mathrm{d} l$, the mean of it was $2.3 \mu \mathrm{g} / \mathrm{d} l$ ( \pm 0.7 S.D.). The dose of $0.25 \mathrm{mg}$ appeared insufficient to suppress the morning rise in cortisol. This suppressibility did not correlate to the body weight as shown in Fig. 2. The duration of the suppression lasted as long as $10 \mathrm{a} . \mathrm{m}$. in the majority of 7 volunteers given with $0.5 \mathrm{mg}$ dexamethasone at $11 \mathrm{a} . \mathrm{m}$. on the previous night and the plasma cortisol was being determined until 1.30 p.m. on the following day.

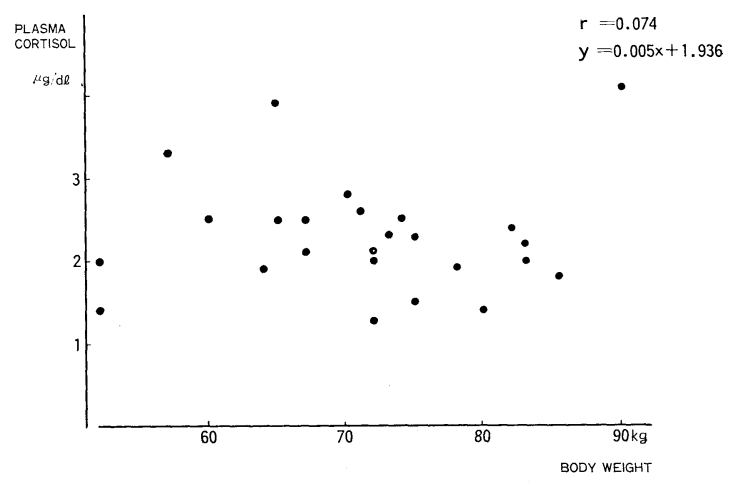

Fig. 2. Relation between the suppressed plasma cortisol and body weight.

Table 1. Plasma cortisol in rapid dexamethasone suppression test in normals

\begin{tabular}{|c|c|c|c|c|c|c|c|c|c|c|}
\hline No. & Name & Sex & Age & $\begin{array}{c}\text { B. W. } \\
\text { kg }\end{array}$ & $\begin{array}{c}\text { B. L. } \\
\mathrm{cm}\end{array}$ & $\begin{array}{c}\text { Dex. mg } \\
0\end{array}$ & $\begin{array}{c}\text { Dex. mg } \\
0.25\end{array}$ & $\begin{array}{l}\text { Dex. mg } \\
0.5\end{array}$ & $\begin{array}{c}\text { Dex. mg } \\
0.75\end{array}$ & $\begin{array}{c}\text { Dex. mg } \\
1.0\end{array}$ \\
\hline 1 & Koyama & $\mathbf{M}$ & 35 & 78 & 173 & 10.5 & & 1.9 & & 2.2 \\
\hline 2 & Shimizu & M & 36 & 80 & 172 & 13.5 & & 1.4 & & \\
\hline 3 & Tamaru & M & 39 & 57 & 163 & 17.6 & 3.4 & 3.3 & 2.7 & 2.8 \\
\hline 4 & Ookura & M & 20 & 74 & 171 & 10.2 & & 2.5 & 1.8 & 1.6 \\
\hline 5 & Sasano & $\mathrm{F}$ & 55 & 65 & 152 & 24.1 & 7.0 & 3.9 & 1.7 & 1.8 \\
\hline 6 & Matsum. & $\mathrm{F}$ & 22 & 52 & 159 & 13.0 & 7.3 & 1.4 & & 1.3 \\
\hline 7 & Tuneya. & $\mathrm{F}$ & 51 & 70 & 163 & 7.5 & & 2.8 & & \\
\hline 8 & Tayama & $\mathrm{F}$ & 38 & 75 & 158 & 15.6 & & 2.3 & & 1.5 \\
\hline 9 & Mizuno & $\mathrm{F}$ & 44 & 83 & 157 & 9.7 & & 2.0 & & \\
\hline 10 & Nakaji. & $F$ & 24 & 65 & 152 & 10.9 & & 2.5 & & \\
\hline 11 & Hoshino & $\mathrm{F}$ & 40 & 67 & 162 & 18.8 & & 2.1 & & \\
\hline 12 & Nakano & $\mathrm{F}$ & 53 & 51 & 150 & 14.4 & & 2.0 & & 2.0 \\
\hline 13 & Honda & $\mathrm{F}$ & 50 & 60 & 153 & 10.7 & & 2.5 & & 2.5 \\
\hline 14 & Urushi. & M & 29 & 82 & 177 & 9.2 & & 2.4 & & 2.0 \\
\hline 15 & Haga & M & 41 & 73 & 164 & 9.1 & & 2.3 & & \\
\hline 16 & Hatuto. & M & 32 & 83 & 169 & 11.4 & & 2.2 & & \\
\hline 17 & Fukuha. & $\mathrm{F}$ & 18 & 72 & 159 & 7.1 & & 1.3 & & \\
\hline 18 & Suzuki & $\mathrm{F}$ & 54 & 65 & 152 & 11.6 & & 3.0 & & \\
\hline 19 & Higuchi & $\mathrm{F}$ & 34 & 72 & 155 & 16.7 & & 2.0 & & \\
\hline 20 & Naiki & $\mathrm{F}$ & 53 & 90 & 149 & 11.8 & & 4.1 & & \\
\hline 21 & Mikami & $\mathrm{F}$ & 38 & 71 & 151 & 13.7 & & 2.6 & & \\
\hline 22 & Ishikawa & M & 34 & 58 & 158 & 23.2 & & 1.6 & & 2.1 \\
\hline 23 & Awano & $\mathbf{M}$ & 17 & 67 & 168 & 16.0 & & 2.5 & & \\
\hline 24 & Kishi & M & 33 & 72 & 170 & 19.0 & & 2.1 & & \\
\hline 25 & Matsukawa & $\mathrm{F}$ & 35 & 75 & 154 & 10.5 & & 1.5 & & \\
\hline 26 & Hosoya & $\mathbf{M}$ & 66 & 85 & 165 & 7.7 & & 1.9 & & \\
\hline \multirow[t]{2}{*}{27} & Kanazawa & $\mathrm{F}$ & 32 & 64 & 155 & 10.6 & & 1.9 & & \\
\hline & Mean & & & & & $13.1 \pm 4.5$ & & $2.3 \pm 0.7$ & & $2.0 \pm 0.5$ \\
\hline
\end{tabular}


The completeness of the suppression of episodic variation of plasma cortisol in the early morning following the single oral dose of $0.5 \mathrm{mg}$ dexamethasone was studied in two normal volunteers as shown in Fig. 3. The plasma cortisol was completely suppressed at any time during their sleep and in the early morning.

\section{Patients :}

The case described in the case report of this paper was studied for the episodic variation of the plasma cortisol under the basal state and following the 0.5 or $1.0 \mathrm{mg}$ of dexamethasone as shown in Fig. 4. It was apparent that $0.5 \mathrm{mg}$ dexamethasone was not sufficient to suppress the rise in cortisol

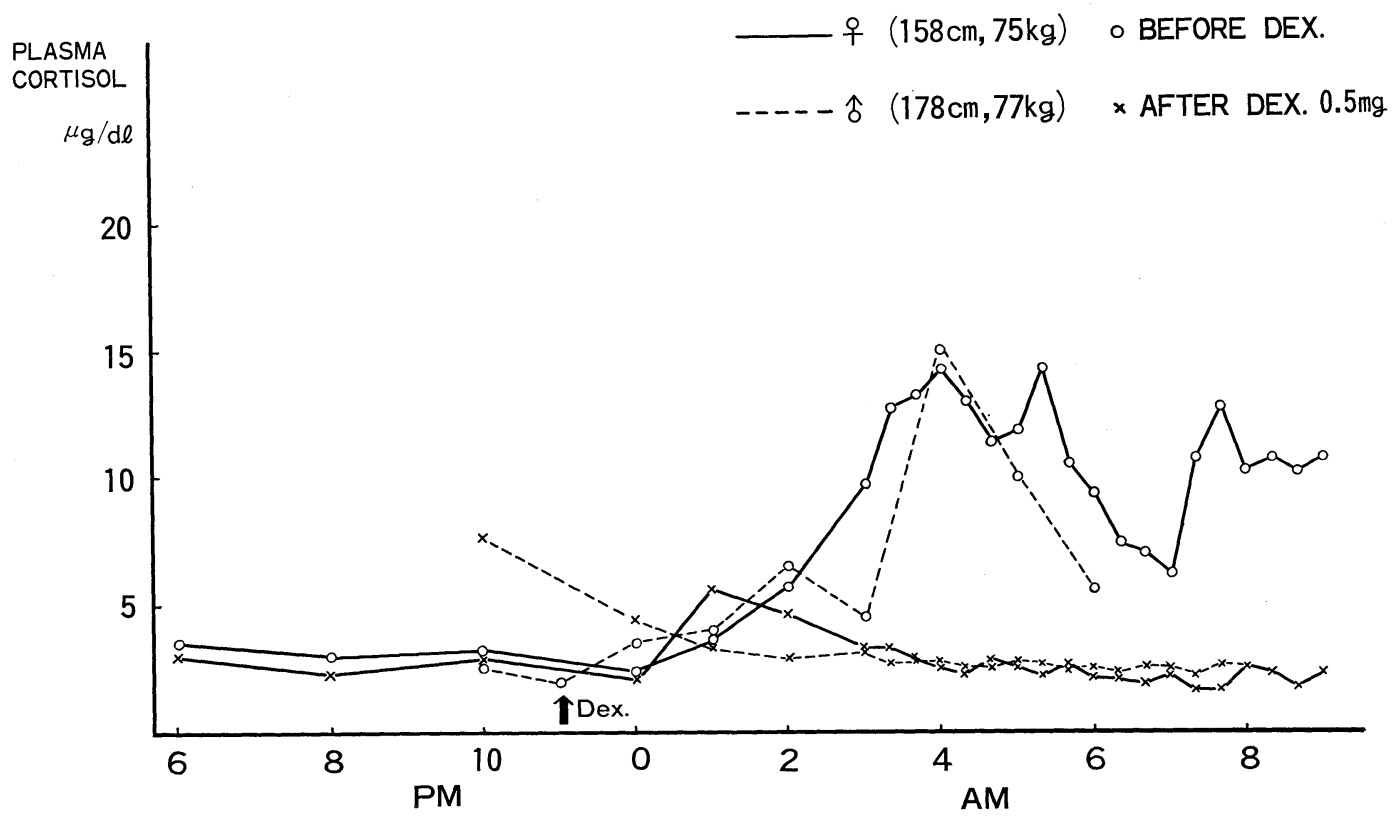

Fig. 3. Suppression of plasma cortisol after a single oral dose of $0.5 \mathrm{mg}$ of dexamethasone administration in two normals.

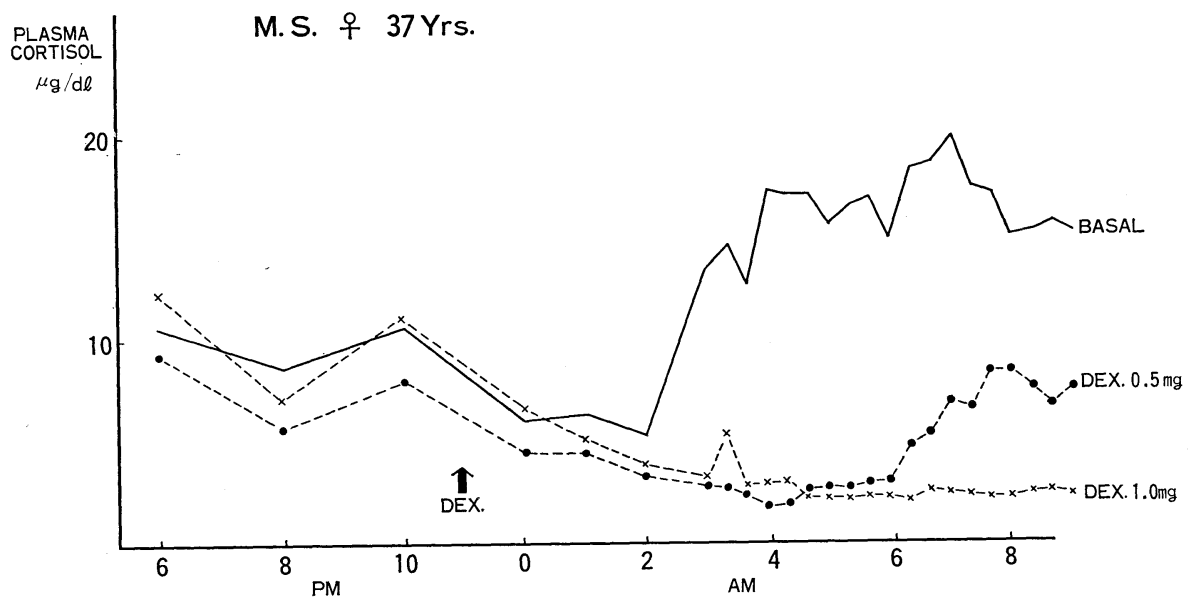

Fig. 4. Suppression of plasma cortisol after a single oral dose of $0.5 \mathrm{mg}$ or $1.0 \mathrm{mg}$ of dexamethasone in a "low dose" suppressible Cushing's disease, M. S. 
in the early morning while $1.0 \mathrm{mg}$ was sufficient. We experienced the other case of the unsuppressible plasma cortisol following $0.5 \mathrm{mg}$ dexamethasone which was currently under investigations.

Plasma dexamethasone:

To correlate the level of plasma dexamethasone with plasma cortisol, the plasma dexamethasone was measured during the overnight suppression test of the two patients with Cushing's disease under discussion and two control subjects. As shown in Fig. 5, the plasma dexamethasone level was not quite differnt in those two groups.
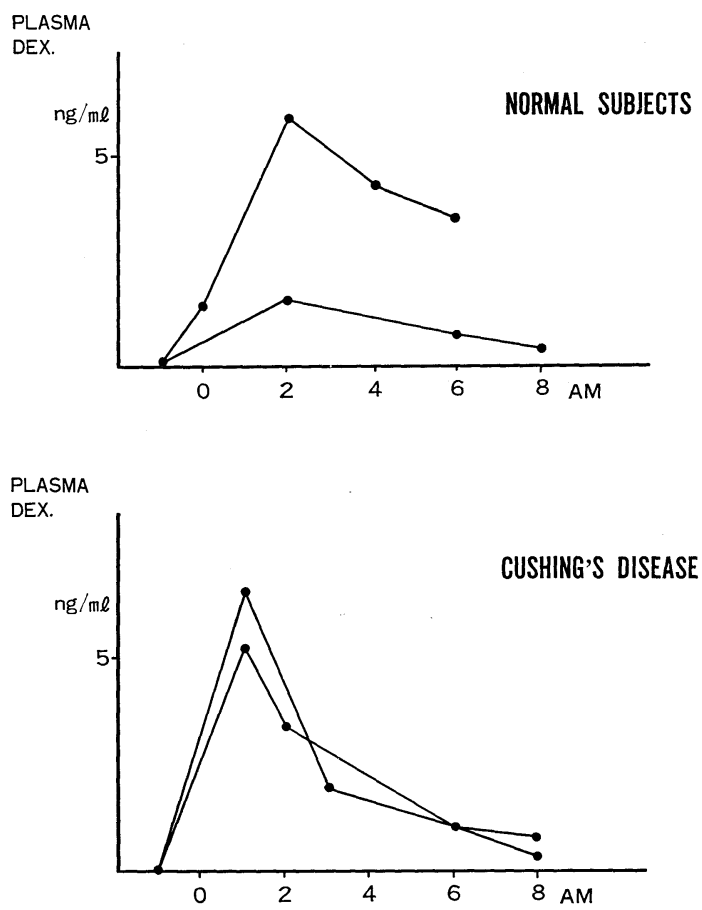

Fig. 5. Plasma levels of dexamethasone in two normals and two "low dose" suppressible Cushing's disease after a single oral dose of $0.5 \mathrm{mg}$ of dexamethasone.

\section{Discussion}

The diagnosis of Cushing's disease is mainly established on the functional basis. Therefore the demonstration of the unsuppressibility of the plasma cortisol is regarded as the most important criterion of the diagnosis. The dosage of glucocorticoid to suppress either the hypothalamus to counteract the neural drive to secrete CRF or the pituitary to counteract the CRF action has been determined empirically by Liddle (1960) and Nugent et al. (1965) and their recommended dosage was widely accepted as the most reliable one to differentiate the disease from the normal.

In the literature, however, those cases reported by Cassidy et al. (1966), Sawin (1968) were suppressed normally with daily dose of $2 \mathrm{mg}$ dexamethasone, as 11 cases in Japan. The present case was also suppressed normally with either a daily dose of $2 \mathrm{mg}$ of dexamethasone or a single dose of $1 \mathrm{mg}$. The diagnosis of Cushing's disease was substantiated by the increased urinary 17-OHCS which showed little periodic variation, superresponse to metyrapone, ${ }^{131}$ I-cholesterol scanning as well as by her clinical course. The adrenal pathology confirmed the diagnosis. Her adrenals weighed $14.3 \mathrm{~g}$ in total which was close to $15.46 \mathrm{~g}$, the average weight of 92 cases of Cushing's disease who underwent the bilateral adrenalectomy. We considered the unsuppresibility of the plasma cortisol in the early morning in this particular patient, following the single oral administration of $0.5 \mathrm{mg}$ of dexamethasone to be a meaningful important finding. The unsuppressibility was demonstrated repeatedly in this particular patient and never in the control normals. One might suspect the different metabolism of dexamethasone in these particular types of Cushing's disease. Even though the number of cases was small, we could not find any marked difference in the disappearance of 
plasma dexamethasone between the Cushing's disease and the conrol. Therefore it seemed that the unsuppressibility found in this particular case of Cushing's disease was not due to the lack of glucocorticoid activity.

We have concluded in this paper that, at least for the sorting out of the mild case with Cushing's disease, $0.5 \mathrm{mg}$, rather than $1.0 \mathrm{mg}$ of dexamethasone is to be administered orally at 11 p.m. for the rapid suppression test.

\section{Acknowledgement}

The authors express their appreciation to Miss J. Joko and Mrs. M. Arakawa for their excellent technical assistances.

This work was supported in part by the Research Fund of the Ministry of Welfare, Japan,

\section{References}

Cassidy, C. E., P. S, Rosenfeld and M. A. Bokat (1966). J. Clin. Endocr. Metab. 26, 1181.

Lee, Y.-S. and N. Osawa (1974). Endocrinol. Japon. $21,481$.

Liddle, G. W. (1960). J. Clin. Endocr. Metab. 20, 1539.

Meikle, A. W., L. G. Lagerquist and F. H. Tyler (1973). Steroids 22, 193.

Nugent, C. A., T. Nichols and F. H. Tyler (1965). Arch. Int. Med. 116, 172.

Sawin, C. T. (1968). Ann. Int. Med. 68, 624. 